Results Mean serum ferritin, and ferritin/iron ratio were significantly higher among febrile children when compared to controls. Mean serum iron levels were significantly lower among febrile patients and in the subgroup of children who had bacterial infections when compared with children who had viral infections and those who had a non-infectious illness.

Conclusion Serum iron and ferritin/iron ratio may be clinically useful markers for the differentiation of bacterial from viral infection in the emergency department. Further studies are needed to confirm our findings and to further explore the role of iron metabolism in paediatric infections.

\section{PO-0199 MICROSCOPIC OBSERVATION DRUGS SUSCEPTIBILITY (MODS): A PROMISING CULTURE-BASED ASSAY TO DIAGNOSING TUBERCULOSIS IN CHILDREN}

${ }^{1} \mathrm{H}$ Nataprawira, ${ }^{2}$ Parwati. ${ }^{1}$ Child Health, Faculty of Medicine Universitas Padjadjaran, Bandung, Indonesia; ${ }^{2}$ Clinical Pathology, Faculty of Medicine Universitas Padjadjaran, Bandung, Indonesia

\subsection{6/archdischild-2014-307384.856}

Background To confirming diagnosis tuberculosis (TB) in children is still challenging worldwide, particularly in low-resource settings. The Microscopic Observation Drug Susceptibility (MODS) is promising whilst this assay improved yield recovery of Mycobacterium tuberculosis that is faster and better as compared with traditional culture method. In Indonesia, MODS culture study in adults $\mathrm{TB}$ have been reported but not for childhood TB because of the cost.

Methods Gastric aspirate specimen were collected from 10 children aged $\leq 14$ years suspected has having severe TB admitted to paediatric ward Hasan Sadikin Hospital-Bandung-Indonesia in 2011 examined by acid-fast bacilli (AFB) and cultured by MODS in Department of Clinical Pathology. We presumed TB for those children who responded clinically at the end of their TB treatment. The outcome measurements were proportion of specimens that culture positive by MODS.

Results Eight of 10 children were preadolescents and adolescents age. All children were severe malnourished, but one. Tuberculous meningitis was diagnosed in $3 / 10$ children and others seven children diagnosed as spondylitis TB (1), destroyed lung TB (1), cutaneous TB (1), extensive pneumonic TB (4). All had positive AFB, but two. MODS provided significantly more positive cultures (8/10) and occurred in positive AFB children. Eight children were on directly-observed treatment shortcourse (DOTS).

Conclusion Isolation of Mycobacterium tuberculosis from severe TB children demonstrated greater yield by MODS culture assay and more frequent in preadolescent and adolescents children.

\section{PO-0200 SPHINGOMONAS PAUCIMOBILIS: A CAUSE OF OTOMASTOIDITIS COMPLICATED WITH SUBPERIOSTEAL ABSCESS IN AN IMMUNOCOMPETENT CHILD}

G Nuncio Benevides, N Hein, D Swei Lo, AE Ferronato, SLB Ragazzi, CRM Yoshioka, M Hirose, DM Cardoso, AE Gilio. Department of Pediatrics, University Hospital of University of Sao Paulo, São Paulo, Brazil

\subsection{6/archdischild-2014-307384.857}

We present the first case of Sphingomonas paucimobilis otomastoiditis, complicated with subperiosteal abscess in an immunocompetent child.

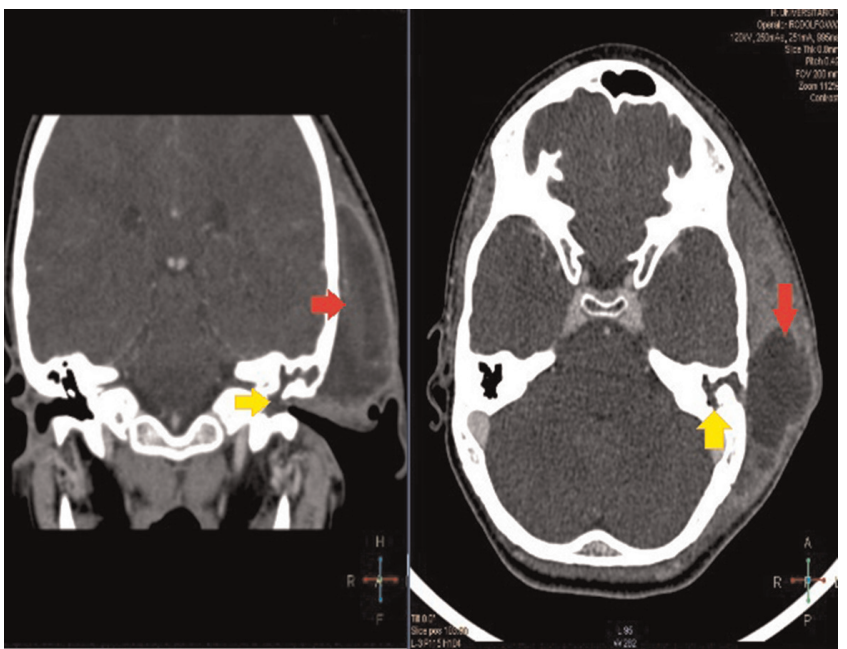

Abstract P0-0200 Figure 1 CT scan showing left otomastoiditis (yellow arrow) associated with a large collection exterior to the temporal bone (red arrow)

Case Report A 11-year-old boy with previous diagnosis of chronic bilateral otitis media presented with 20 days of fever, otalgia, otorrhea, progressive retroauricular swelling with protrusion of the left ear and worsening of the symptoms despite 15 days of Amoxicilin. A CT scan was performed (Figure 1). Blood tests showed WBC $22,4 \times 109$ (neutrophils $81,2 \%$ ) and CRP of 142. Surgical drainage of the abscess found a large amount of purulent foetid secretion. We empirically initiated Ceftazidime and Clindamycin. He remained well, with defervescence and resolution of the scalp deformation. Control test showed WBC 7,4 $\times 109$ (neutrophils 58,7\%) and CRP of 6. Culture of the abscess grew Sphingomonas paucimobilis. The patient was discharged with Cyprofloxacin and returned after 1 month in our clinic recovered.

Discussion S. paucimobilis is an aerobic gram-negative bacillus that rarely infects humans, most commonly immunocompromised and hospitalised patients. We searched the literature for $S$. Paucimobilis infections in children and found 47 reported cases (Table 1). The most common diagnosis is isolated bacteremia and there are no previous report of otomastoiditis. It is related to sporadic or epidemic infections, leading to just one published case of death in children. S. paucimobilis infection has been increasingly reported over the years and it's a more important pathogen than previously thought.

Abstract P0-0200 Table 1 Clinical characteristics of paediatric cases of Sphingomonas paucimobilis infection in our literature review

\begin{tabular}{|c|c|c|c|c|c|}
\hline Condition & $\begin{array}{c}\text { Number of } \\
\text { cases }\end{array}$ & $\begin{array}{c}\text { Mean Age } \\
\text { (range) }\end{array}$ & Gender & $\begin{array}{c}\text { Higid/Previous } \\
\text { Commorbity } \\
\text { (number of cases) }\end{array}$ & $\begin{array}{c}\text { Acquired Hospital / } \\
\text { Community } \\
\text { (number of cases) }\end{array}$ \\
\hline \multicolumn{6}{|c|}{ Isolated Bacteremia or } \\
\hline UII & 2 & $4,5 \mathrm{~m}(4-5 \mathrm{~m})$ & IM:IF & $2 / 0$ & $0 / 2$ \\
\hline CAPD Penitonitis & 1 & $14 \mathrm{y}$ & $0 \mathrm{M}: \mathrm{IF}$ & $0 / 1$ & $1 / 0$ \\
\hline Cervical Adenitis & 1 & $8 y$ & IM:OF & $1 / 0$ & $0 / 1$ \\
\hline $\begin{array}{l}\text { CNS Infection or } \\
\text { Abscess }\end{array}$ & 2 & $6-10 y$ & $1 \mathrm{M}: 1 \mathrm{~F}$ & $2 / 0$ & 1/1 \\
\hline $\begin{array}{l}\text { Osteomielitis/Septic } \\
\text { Arthritis }\end{array}$ & 1 & $16 y$ & $1 \mathrm{M}: 0 \mathrm{~F}$ & $0 / 1$ & ? \\
\hline Pneumonia & 1 & $5 y$ & IM:OF & $1 / 0$ & $0 / 1$ \\
\hline Otomastoiditis** & 1 & $11 \mathrm{y}$ & IM:OF & $1 / 0$ & $0 / 1$ \\
\hline Total & 47 & $5,3 y(0-17 y)$ & $1,7 \mathrm{M}: 1 \mathrm{~F}$ & $20 / 27$ & $27 / 19$ \\
\hline \multicolumn{6}{|c|}{ 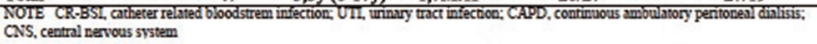 } \\
\hline \multicolumn{6}{|l|}{ - One case of death } \\
\hline \multicolumn{6}{|l|}{ *Present study } \\
\hline ? The author could not defin & if it was acqui & Ihenin & & & \\
\hline
\end{tabular}

